\title{
LAS DESIGUALDADES SOCIALES Y URBANAS EN LA CIUDAD DE MÉXICO: ¿DÓNDE QUEDA EL DERECHO A LA VIVIENDA?
}

Social and urban inequalities in Mexico City: what right to housing?

\author{
Adriana Huerta Núñez \\ Université du Québec à Montréal \\ huerta_nunez.adriana@courrier.uqam.ca \\ https://orcid.org/0000-0001-5793-6967
}

\section{Hélène Bélanger}

Université du Québec à Montréal

belanger.helene@uqam.ca

https://orcid.org/0000-0002-6749-9673

RESUMEN: Este artículo explora las características de los procesos de gentrificación y de exclusión socio-espacial que surgen con los proyectos de revitalización urbana, los mismos que son puestos en marcha bajo un modelo de ciudad neoliberal. Para estudiar el contexto de la Ciudad de México, realizamos una investigación documental que incluyó el análisis de instrumentos jurídicos, políticas públicas y demás programas gubernamentales que, desde el año 2000, han implicado un desarrollo urbano caracterizado por la insuficiente construcción de vivienda social y el auge de inversiones inmobiliarias de lujo. Este análisis demuestra que la asociación de poderes públicos y de intereses privados ha generado condiciones de marcada desigualdad, lo que nos lleva a cuestionar el derecho a la ciudad y a la vivienda para las poblaciones de bajos recursos o marginalizadas, que son desplazadas simbólicamente o de facto.

Palabras clave: Revitalización urbana, gentrificación, derecho a la ciudad, derecho a la vivienda, Ciudad de México.

ABSTRACT: This article explores the characteristics of gentrification and socio-spatial exclusion processes emerged with urban revitalization projects; those ones are launched under the neoliberal city model. In order to study 
Mexico City's context, we did a documentary research including the analysis of several legal instruments, public policies among other government programs dating from 2000. These have entailed an urban development characterized by an insufficient construction of social housing and a luxury real estate boom. This analysis shows that the association between public authorities and private interests has produced conditions of marked inequality. This poses the question upon the right to the city and the right to housing for marginalized or low-income populations, that are symbolically or de facto displaced.

KeYwords: Urban revitalization, gentrification, right to the city, right to housing, Mexico City.

\section{Introducción}

La revitalización de barrios de la ciudad neoliberal es el punto de partida de esta reflexión, que parte de los procesos de gentrificación y de exclusión socio-espacial que han sido iniciados o alimentados por los poderes públicos, como en el caso de la Ciudad de México. Si bien, el mejoramiento del medio físico y de las condiciones de vida es el objetivo central de los proyectos y programas de revitalización, éste no constituye su único propósito, puesto que, a la reducción o reversión de la degradación del entorno construido, se le añade la captación de nuevas inversiones privadas.

Los desarrollos inmobiliarios residenciales, los nuevos comercios y otros servicios permiten la atracción de visitantes, turistas, trabajadores y nuevos residentes con mayor poder adquisitivo, excluyendo simbólicamente o de facto, a las poblaciones pobres o marginalizadas. A la par, la reglamentación en materia de desarrollo urbano y los programas de vivienda social resultan poco funcionales, ya que se desvían de su misión, que es el garantizar una vivienda adecuada y accesible.

El objetivo del presente artículo es el de explorar las características de este desplazamiento simbólico en el contexto de la revitalización urbana, como parte de políticas públicas y de programas de vivienda que buscan la densificación poblacional. Tales medidas gubernamentales han permitido paralela- 
mente el desarrollo inmobiliario y la expansión de actividades económicas en función de una población con alto poder adquisitivo.

Estas desigualdades llevan a cuestionar el derecho a la ciudad y a la vivienda para las poblaciones de bajos recursos o marginalizadas, derechos fundamentales que se encuentran presentes tanto en instrumentos jurídicos internacionales como nacionales. Es posible constatar esta misma lógica detrás de la revitalización de los espacios públicos, que han significado la atracción de nuevos usuarios y la exclusión simbólica de poblaciones marginalizadas.

Además de realizar un análisis desde el ángulo teórico, profundizando en la revitalización de los espacios públicos y en las características generales de los procesos de gentrificación en América Latina, este trabajo también propone abordar los efectos del neoliberalismo en el espacio urbano de la Ciudad de México, partiendo de los diversos instrumentos jurídicos, políticas públicas y demás programas gubernamentales que han marcado un desarrollo urbano caracterizado por la insuficiente construcción de vivienda social y el auge del sector inmobiliario. Para tal efecto, se tomará como punto de partida el año 2000, la llegada al gobierno de la ciudad de Andrés Manuel López Obrador (2000-2005) que marcó una pauta en la densificación de las áreas centrales de la ciudad y en la construcción de infraestructura.

\section{La ciudad neoliberal y la revitalización: ¿para qué y para quiénes?}

En las últimas décadas, las inversiones público-privadas se han orientado a la creación de un modelo de ciudad neoliberal en la que predominan los proyectos y programas de revitalización de espacios. Tales proyectos están pensados y justificados en términos de beneficios económicos y de atracción de inversiones privadas, pues integran desarrollos inmobiliarios residenciales, nuevos comercios, entre otros servicios que permiten atraer visitantes, turistas, trabajadores y nuevos residentes, limitando de esta manera el derecho a la ciudad (Lefebvre, 1968) para otro tipo de residentes en condiciones menos afortunadas (Bélanger, 2018). 
Bajo esta lógica neoliberal se constituyen nuevas configuraciones de los espacios públicos que inciden, a su vez, en las formas de apropiación, como la conformación de espacios privados de uso público y de espacios públicos de uso privado. En principio, con la proliferación de centros comerciales, algunos trabajos (Lulle \& Paquette, 2007; Duhau \& Giglia, 2010) señalan que ciertas actividades cotidianas vinculadas al uso de espacios públicos como plazas, parques y demás sitios han cedido terreno frente a espacios bajo control privado.

En segunda instancia, Portal (2016) explica que los cambios en la apropiación colectiva de los espacios públicos se explican por sus propias condiciones simbólicas y materiales, que también se determinan por las relaciones de poder y las prácticas culturales y de clase que ahí tienen lugar. Desde esta perspectiva, Duhau \& Giglia (2010) señalan una segmentación y estratificación social en los usos del espacio público: «existen lugares específicos para públicos especificos, según su nivel de recursos y su ubicación en la metrópoli» (p. 404), de manera que, para los estratos altos y medios, los sitios públicos que permiten el acceso a cualquier persona resultan poco atractivos.

De tal forma que, en la ciudad neoliberal, se observa una tendencia a la revitalización del espacio urbano orientado al consumo en beneficio de estratos medios y altos. Mientras que otros ámbitos que conciernen el bienestar de amplios sectores de la población, como la construcción de vivienda social, han sido puestos en manos del sector privado (Olivera Martínez, 2014).

«La planificación territorial [...] es también favorecer ciertos modos de vida y de excluir otros prolongadamente» (Pattaroni et al., 2009; p. 8, traducción libre). Aun cuando los programas y políticas de ordenación o las acciones de revitalización persiguen objetivos inclusivos que responden a las necesidades de las poblaciones locales, la nueva atractividad de los espacios favorece determinados modos de vida y ciertas poblaciones, además puede dificultar la convivencia entre los grupos e incluso detonar tensiones y conflictos. 


\section{I Revitalización y gentrificación}

Es a inicios de los años 1960, cuando la socióloga Ruth Glass concibió el término gentrificación luego de su observación del «regreso de los gentries» ${ }^{1}$ a los barrios centrales de Londres (Glass, 1989). Esta dinámica no es exclusiva de Londres, trabajos posteriores han identificado el mismo fenómeno en otras ciudades de Europa, pero también en América y en otras latitudes. No obstante, se observan diferencias en cuanto al origen del fenómeno (los factores detonantes), sus alcances, su rapidez y sus impactos en el medio físico y social de los entornos afectados.

Para algunos investigadores, la gentrificación es el resultado de un proceso, en principio marginal, en el que se acumulan las decisiones individuales de hogares poseedores de un capital cultural mas importante que el de la población local (los cuales no necesariamente son poseedores de un mayor capital financiero, en las primeras fases) (Rose, 1984; Ley, 1996). Mientras que, para otros investigadores, la gentrificación sería el resultado, en primer lugar, del «regreso del capital» a los barrios centrales en declive, a través de proyectos de redesarrollo (Smith, 1996). En algunos casos este (re)desarrollo (Smith, 1996) se haría a menor escala, en los terrenos vacíos, lo que Rose (2010) denomina gentrificación instantánea (Davidson y Lees, 2010).

Después de 50 años de investigaciones, la gentrificación parece haber sido convertida en un concepto comodín y omnipotente que designa toda dinámica de transformación de barrios y el ascenso del estatus socio-económico de éstos, sin importar cuáles sean sus orígenes, actores o procesos. Lo que «hace de la gentrificación, gentrificación» (Redfern, 2003) parece todavía difícil de definir (Chabrol et al., 2016; Bidou-Zachariasen, 2003). En la búsqueda de su ADN, Chabrol et al. (2016) subrayan que la gentrificación es plural, cada proceso es influenciado por factores locales y globales, además de otros procesos paralelos como el empobrecimiento, la inmigración y la revitalización. En suma, para ellos la gentrificación es «una relación de desigualdad social en la apropiación del espacio» (Chabrol et al. 2016: p. 70, traducción libre).

1. El uso de gentry(ie) hace referencia a una clase alta, a la nobleza o una alta burguesía, sin embargo, existen debates terminológicos con respecto al uso y traducción al castellano de esta palabra. 
A pesar de todo, la permeabilidad del concepto de gentrificación alimenta la crítica sobre su validez para designar la transformación de los entornos de vida (Chabrol et al., 2016; Lees, Slater y Wyly, 2008; Smith, 2002) y más aún en América Latina, donde los trabajos son más recientes, principalmente entre los investigadores mexicanos. Si algunos han «adoptado mecánicamente» el concepto, otros lo han adaptado al contexto; donde algunos investigadores no ven más que la importación de un concepto, estos últimos lo han simplemente rechazado, percibiendo únicamente la importación de un concepto anglosajón para explicar un contexto geográfico, político, económico, social y cultural diferente (Casgrain y Janoschka, 2013; Janoschka, Sequera y Salinas, 2014; Hiernaux y Gonzázlez, 2014; Delgadillo, 2016).

Entre las diversas especificidades de la gentrificación que están determinadas por el contexto geográfico, se encuentran: el carácter simbólico que implica la recuperación de los sitios por la clase media, principalmente en los centros históricos (Jones et Varley, 1999; Bélanger, 2008); la importancia de la privatización de los espacios públicos como forma de control y de apropiación (Janoschka, et al., 2014); y la puesta en práctica de políticas higienistas que buscan la erradicación de prácticas y usuarios tradicionales (Díaz y Cuberos, 2018).

En suma, se privilegian los ejes estratégicos de desarrollo urbano para el turismo, patrimonio, espacio público, que junto con los usos mixtos y corporativos son los que justifican la renovación urbana en áreas previamente abandonadas por inversiones públicas y privadas, lo cual combina directamente los intereses inmobiliarios y empresariales al asociarse con los públicos para atraer consumidores, residentes y turistas, desplazando a sectores populares. (Olivera Martinez, 2015: 104)

Desde este ángulo, aunque las operaciones de revitalización pretendan ser inclusivas para toda la población en general, lo cierto es que el diseño y la programación de actividades de los espacios intervenidos, llevados a cabo de acuerdo con normas modernas «internacionales», atraen a ciertas categorías de usuarios. Por ende, los espacios son saneados para atender a los estándares de nuevos usuarios, sin que se excluya de manera explícita a aquellos que resultan «menos deseables» (Bélanger, 2018). 
En este sentido, la gentrificación que es iniciada o acelerada por los proyectos de revitalización resulta de interés en nuestro trabajo, puesto que las prioridades de inversión de los actores públicos y privados, desde nuestra perspectiva, contribuyen a la desigualdad de las relaciones sociales de la apropiación del espacio.

\section{CDMX: ciudad global, ciudad neoliberal}

La Ciudad de México ha pasado por un proceso de reforma política desde 1997, año en que se llevó a cabo la primera elección ciudadana para jefe de gobierno por vía electoral. A partir de ese momento, la ciudad ha tenido gobiernos que suelen ser considerados de izquierda, y en cuyo discurso se ha puesto un énfasis en la política social. Igualmente, se ha buscado consolidar la imagen de la ciudad a nivel internacional a través de diversos mecanismos, que van desde la creación de una marca (CDMX), hasta la activa promoción de la política social en foros y organismos internacionales.

Tanto el derecho a la ciudad y a la vivienda han estado presentes en tales iniciativas, lo que se constata con la firma de compromisos internacionales como la Carta de la Ciudad de México por el Derecho a la Ciudad en 2007. Sin embargo, como lo menciona Delgadillo (2012), estas acciones no se ven concretadas en la planificación urbana, pues siguen realizándose megaproyectos sin consultar a la población. Así, se exacerban las desigualdades al priorisarse los intereses particulares del capital privado.

Uno de los efectos de esta planeación urbana son las desigualdades socio-espaciales percibidas en la Ciudad de México. Éstas son producto de las reestructuraciones económicas que han buscado su inserción global, con el asenso del sector de servicios como principal área de especialización económica de la ciudad (Parnreiter, 2002). Por lo cual, la tercerización de la economía de la Ciudad de México ha tenido diversas consecuencias sociales, tales como la disparidad en el ingreso - el empobrecimiento- y el crecimiento del sector informal, como efecto directo del deterioro de las condiciones laborales (ibíd). Aunado a ello, la implementación de políticas neoliberales ha propiciado la fragmentación, segregación y privatización. De tal manera que, 
actualmente, la ciudad presenta múltiples contradicciones evidentes en un espacio urbano polarizado socialmente, como se muestra con las marcadas disparidades en los índices de pobreza en las alcaldías que componen la urbe. ${ }^{2}$

Tal disparidad en la distribución de la riqueza incide en las configuraciones espaciales de la Ciudad de México, como se observa con la privatización de espacios residenciales, los llamados barrios cerrados, que desde la década de 1980 comenzaron a ser vistos como una opción residencial para sectores acomodados de la población en busca de homogeneidad social, limpieza y seguridad (Aguayo Ayala, 2016; Janoschka y Borsdorf, 2006).

Desde otro ángulo, algunas autoras (Aguayo Ayala, 2016; Olivera Martínez, 2014; Pérez Negrete, 2016) señalan la relevancia adquirida por los sectores financiero e inmobiliario dentro de la planificación urbana de la Ciudad de México, que de igual manera ha significado la orientación de un modelo de ciudad en favor de sus propios intereses. En este orden de ideas, las autoras apuntan hacia un incremento de la inversión inmobiliaria para la realización de megaproyectos de infraestructura en determinadas áreas de la ciudad; tales inversiones buscan la atracción de capitales al favorecer los usos corporativos y residenciales, que van destinados a las élites.

En este caso se encuentran las acciones encaminadas a la rehabilitación del centro histórico de la Ciudad de México; las edificaciones renovadas tienen usos culturales, corporativos o comerciales, con una oferta enfocada principalmente a las clases altas y medias (Olivera Martínez, 2014). Para Víctor Delgadillo (2017), esta recuperación, entre otras cosas, ha tenido un sesgo empresarial, pues ha beneficiado al principal empresario del país, Carlos Slim; al mismo tiempo, ha traído consigo «efectos excluyentes y privatizadores del patrimonio urbano, que por definición es colectivo. Además de las tendencias de erosionar la dimensión pública del espacio público» (p. 199).

2. La Ciudad de México se encuentra organizada territorial y administrativamente por 16 alcaldías, anteriormente llamadas delegaciones.

De acuerdo con información del Consejo Nacional de Evaluación de la Política de Desarrollo Social (CONEVAL), en 2015, el menor porcentaje de personas en situación de pobreza en esta ciudad se ubicaba en las alcaldías Benito Juárez y Miguel Hidalgo, con $5 \%$ y $7 \%$ respectivamente. Mientras que las alcaldías con el mayor porcentaje fueron Milpa Alta y Xochimilco, con 49,2\% y 40,5\% correspondientemente.V. https:// www.coneval.org.mx/coordinacion/entidades/DistritoFederal/Paginas/pobreza_mu$\underline{\text { nicipal2015.aspx }}$ 
Estos proyectos también están asociados con el desarrollo de nuevas centralidades, a través de alianzas entre los sectores público y privado. Si bien, las inversiones inmobiliarias han favorecido la construcción de edificios de oficinas principalmente en las alcaldías centrales de la ciudad (Cuauhtémoc, Miguel Hidalgo y Benito Juárez), esta geografia corporativa (Parnreiter, 2011) también integra el desarrollo de otras áreas del poniente de la capital, como son la transformación de la zona de Santa Fe, anteriormente un basurero, y de lo que se conoce como Nuevo Polanco, una zona industrial que se encontraba en cierto abandono.

\section{La lógica neoliberal de los instrumentos de planeación urbana de la Ciudad de México}

La lógica neoliberal que conlleva la reducción de la intervención del Estado y el aumento de la participación del sector privado en diversas áreas ha marcado la estructura urbana de la Ciudad de México desde la década de 1980, y con ello las condiciones de vida de sus habitantes. Así, el papel del Estado se ha visto orientado hacia la creación de leyes, programas y políticas públicas en materia de vivienda y de desarrollo urbano, que han causado los marcados niveles de desigualdad socio-espacial que persisten actualmente en la ciudad (tabla 1). En este contexto, el Estado se dispuso como controlador de la propiedad del suelo para fines privados, dando así un impulso a las inversiones inmobiliarias, tanto de capitales locales como externos, lo que se tradujo en un auge del mercado inmobiliario, en programas de renovación urbana y en procesos de gentrificación (Olivera Martínez, 2014).

En lo que concierne a la política de vivienda, diversos trabajos (Coulomb, 2010; Schteingart, 2016) apuntan al papel del Estado como un «facilitador» que pasó de ser el controlador de la producción y comercialización, a ser únicamente el encargado de fomentar la oferta mediante el otorgamiento de créditos para adquisición de vivienda social. Bajo este esquema, la producción de vivienda se confiere al sector inmobiliario, quien a su vez determina las características y la ubicación de las viviendas, principalmente en función de los costos de la tierra y del margen de ganancia generado por la venta de estas (Salinas Arreortua \& Soto Delgado, 2018). 
De tal manera que, por un lado, se privilegia la construcción de desarrollos inmobiliarios destinados a poblaciones con un mayor poder adquisitivo, en detrimento de la vivienda social; mientras que, por otro lado, las porciones de tierra, alejadas del centro de la ciudad y en ocasiones desprovistas de servicios básicos, se convierten en opciones de vivienda para las poblaciones de bajos recursos.

Aunada a esta política habitacional segregativa (Schteingart, 2016) puesta en marcha principalmente por el gobierno federal, ${ }^{3}$ se observan los efectos poco incluyentes de las políticas locales que desde el año 2000 han buscado la densificación de la ciudad central y la contención de la expansión urbana. Entre estas medidas se encuentran el Bando 2 y la posterior Norma de ordenación 26, dos instrumentos jurídicos actualmente suspendidos que han resultado detonantes del auge del sector inmobiliario en la ciudad, ya que han permitido la construcción de viviendas para un reducido sector de la población, y el aumento de la plusvalía en ciertas áreas de la ciudad.

El Bando 2, fue un edicto emitido en el 2000 por el jefe de gobierno en turno Andrés Manuel López Obrador, que tuvo como principal objetivo la densificación de las cuatro alcaldías centrales de la Ciudad de México (Cuauhtémoc, Benito Juárez, Venustiano Carranza y Miguel Hidalgo) y la contención de la expansión urbana hacia la periferia de la ciudad. Además de revertir el despoblamiento de las áreas centrales y de revitalizar zonas patrimoniales, el Bando 2 responde a una estrategia de ciudad que busca hacer frente a la desaceleración económica, a los problemas ambientales derivados del crecimiento de la ciudad y a la generación de viviendas para familias de bajos recursos (Azuara, González y Tamayo, 2007).

Además de incentivar la inversión del capital privado en las áreas centrales, con el Bando 2 se dispusieron medidas que facilitaron la construcción de vivienda, principalmente de tipo social a través del Instituto de Vivienda de la Ciudad de México (INVI). Sin embargo, algunos trabajos sobre los efectos del Bando 2 (Delgadillo, 2014, 2016; Salinas Arreortua, 2016) muestran que la producción habitacional de tales características no surtió efecto, pues

3. Dentro de estos instrumentos están los Planes Nacionales de Desarrollo 2007- 2012 y 2013-2018; los Programas Nacionales de Vivienda 2008-2012 y 2014-2018, y la Ley General de Asentamientos Humanos. 
los desarrolladores inmobiliarios construyeron viviendas para la población de ingresos medios y altos, y por ende los precios del suelo aumentaron en dichas alcaldías.

Este mismo efecto contrario se observa con la implementación de la Norma de ordenación 26 para incentivar la vivienda de interés social y popular. Planteada como una sustitución del Bando 2, esta norma ofrecía facilidades a los desarrolladores inmobiliarios para la construcción de viviendas sociales, permitiendo al mismo tiempo la construcción de un mayor número de niveles - y con ello de viviendas - aumentando el margen de ganancia. No obstante, más allá de solucionar los problemas de escasez de conjuntos habitacionales de tipo social, esta norma es considerada un mecanismo que justifica los intereses de los desarrolladores inmobiliarios y que mercantiliza la vivienda en función de un sector reducido de la población (Salinas Arreortua \& Soto Delgado, 2019), pues los precios reales de venta de éstas fueron superiores a los establecidos por tal norma.

También en el ámbito local, la Ley de Desarrollo Urbano de la Ciudad de México es otro de los ordenamientos que ha favorecido la acción del sector privado y el auge del sector inmobiliario en la capital de la República mexicana. En esta ley se prevén instrumentos y figuras que plantean esquemas de financiamiento público-privado que no son del todo claros, además de que conllevan la alteración de los usos de suelo y el aumento de la densidad. Entre estos se encuentran los Sistemas de Transferencia de Potencialidades de Desarrollo Urbano, los Polígonos de Actuación, los Sistemas de Actuación por Cooperación (SAC) y las Áreas de Gestión Estratégica (AGE).

Dichos instrumentos han favorecido la inversion inmobiliaria para la realización de proyectos de infraestructura urbana en diferentes zonas de la ciudad, reuniendo usos corporativos, comerciales y residenciales destinados a la población de ingreso medio y alto. Algunos ejemplos de este tipo de proyectos son la transformación de lotes industriales en el norte de Polanco, y recientemente la creación del Parque La Mexicana, en un predio ubicado en Santa $\mathrm{Fe}$, una zona de alta plusvalía y donde existe una gran presión inmobiliaria, en el que originalmente se pretendía construir vivienda de tipo social.

Otro de los elementos que configuran una ciudad excluyente son las intervenciones a los espacios públicos orquestadas por el gobierno de la capital, a 
través de la Autoridad del Espacio Público (AEP). Entre las acciones y los programas desarrollados por la AEP, hasta su desaparición en 2018, están la construcción de bajo puentes, el mejoramiento de banquetas, la rehabilitación de parques, entre otros proyectos que en su mayoría, se concentraron en espacios públicos de colonias centrales de la capital que cuentan con alta plusvalía; zonas en donde los programas gubernamentales con fines de recuperación y mejoramiento de espacios públicos tienen un impacto mediático (Quiroz Rothe y Gómez, 2016). Además, algunos de los proyectos desarrollados por la AEP siguen una lógica meramente comercial, como en el caso de la instalación de infraestructura de uso comercial en los bajo puentes de la ciudad.

Tales disposiciones jurídicas y programas públicos muestran una perspectiva contrastante de las acciones en materia de vivienda y de la política social del gobierno de la Ciudad de México, considerado de izquierda. Si bien es cierto que hay una tendencia a privilegiar el desarrollo inmobiliario y la configuración del espacio urbano en beneficio de un sector reducido de la población, también se observan limitados esfuerzos gubernamentales que buscan mitigar la desigualdad. Entre ellos están las acciones para el acceso a la vivienda orientado a los sectores de la población de bajos recursos, principalmente a través de los programas del INVI. También se encuentra el mejoramiento de las condiciones del entorno habitacional de la población de bajos recursos a través del Programa Comunitario de Mejoramiento Barrial (PCMB).

Algunos trabajos (Delgadillo, 2016; Puebla, 2007; Schteingart, 2016) reconocen los aciertos de la política habitacional puesta en marcha a nivel local, que permitió el acceso a la vivienda para las personas con poca capacidad económica; sin embargo, estas investigaciones también muestran las limitaciones de tal política, pues además de estar financieramente sujeta a la voluntad del gobierno en turno, no ha logrado garantizar que la población de escasos recursos permanezca en las zonas centrales de la ciudad ante las presiones del sector inmobiliario.

Mientras que el PCMB, también se muestra como un esfuerzo del gobierno local para mitigar las condiciones de desigualdad. Este programa fue creado en 2007 con la finalidad de impulsar «la construcción y rescate de espacios públicos en barrios, pueblos y colonias populares de la capital» (Gobierno de la Ciudad de México, 2012). Además, el PCMB tuvo un enfoque diferente 
al de la AEP sobre el tratamiento de los espacios públicos, ya que pretendió «fomentar la integración social y reducir las desigualdades por medio de la redistribución de recursos a las comunidades y el mejoramiento de los entornos físicos» (ibid) en los sectores más desfavorecidos de la ciudad, que usualmente se ubican en la periferia. No obstante, como algunos trabajos lo señalan (Ziccardi, 2011; Delgadillo, 2016), la falta de institucionalización del PCMB permitió que fuera usado para fines clientelares o en función de los intereses políticos de los gobernantes en turno.

\section{Tabla I.}

\section{Instrumentos y políticas de planeación urbana en la Ciudad de México}

\begin{tabular}{|c|c|c|c|}
\hline $\begin{array}{l}\text { Ordenamientos, } \\
\text { programas o } \\
\text { acciones guber- } \\
\text { namentales }\end{array}$ & $\begin{array}{l}\text { Periodo de } \\
\text { vigencia }\end{array}$ & Objetivos principales & $\begin{array}{l}\text { Principales efectos en la } \\
\text { urbanización neoliberal }\end{array}$ \\
\hline Bando 2 & $2000-2005$ & $\begin{array}{l}\text { Densificar la ciudad } \\
\text { central y la contener la } \\
\text { expansión urbana. }\end{array}$ & $\begin{array}{l}\text { Construcción de viviendas } \\
\text { para un reducido sector de la } \\
\text { población, y el aumento de } \\
\text { la plusvalía en ciertas áreas } \\
\text { de la ciudad. }\end{array}$ \\
\hline $\begin{array}{l}\text { Instituto de } \\
\text { Vivienda de } \\
\text { la Ciudad de } \\
\text { México (INVI). }\end{array}$ & $\begin{array}{l}\text { 2000- aún } \\
\text { vigente }\end{array}$ & $\begin{array}{l}\text { Incentivar la cons- } \\
\text { trucción de vivienda de } \\
\text { interés social, y el acceso } \\
\text { a la misma para sectores } \\
\text { de bajos recursos. }\end{array}$ & $\begin{array}{l}\text { Efectos limitados debido a } \\
\text { temas presupuestales. Su } \\
\text { acción está financieramente } \\
\text { sujeta a la voluntad del } \\
\text { gobierno en turno. }\end{array}$ \\
\hline $\begin{array}{l}\text { Programas Gene- } \\
\text { rales de Desa- } \\
\text { rrollo Urbano de } \\
\text { la CDMX }\end{array}$ & $\begin{array}{l}2000-2006 \\
2007-2012 \\
2013-2018 \\
2016-2030\end{array}$ & $\begin{array}{l}\text { Determinar la política y } \\
\text { acciones de desarrollo } \\
\text { urbano de la ciudad. }\end{array}$ & $\begin{array}{l}\text { Justifican las interveciones } \\
\text { gubernamentales para } \\
\text { reveritr el deterioro y la } \\
\text { obsolescencia económica en } \\
\text { áreas centrales de la ciudad } \\
\text { (Salinas Arreortua, 2013). }\end{array}$ \\
\hline $\begin{array}{l}\text { Norma de orde- } \\
\text { nación } 26\end{array}$ & $2005-2013$ & $\begin{array}{l}\text { Incentivar la vivienda de } \\
\text { interés social y popular. }\end{array}$ & $\begin{array}{l}\text { Construcción de viviendas } \\
\text { para un sector pequeño de la } \\
\text { población. }\end{array}$ \\
\hline
\end{tabular}




\begin{tabular}{|c|c|c|c|}
\hline $\begin{array}{l}\text { Autoridad del } \\
\text { Espacio Público }\end{array}$ & $2008-2018$ & $\begin{array}{l}\text { «Coordina[r] y ejecuta[r] } \\
\text { proyectos e iniciativas } \\
\text { para crear entornos } \\
\text { urbanos más atractivos, } \\
\text { vibrantes, diversos e } \\
\text { incluyentes, a través de } \\
\text { procesos innovadores } \\
\text { que aprovechen el cono- } \\
\text { cimiento, inspiración y } \\
\text { potencial de sus comuni- } \\
\text { dades». (AEP, } \mathrm{s} / \mathrm{f} \text { ). }\end{array}$ & $\begin{array}{l}\text { Transformación de espacios } \\
\text { públicos en colonias cen- } \\
\text { trales de la ciudad, aumento } \\
\text { de plusvalía en la zona, y } \\
\text { desplazamiento de usuarios } \\
\text { y prácticas tradicionales. }\end{array}$ \\
\hline $\begin{array}{l}\text { Programa Comu- } \\
\text { nitario de Mejo- } \\
\text { ramiento Barrial } \\
(\mathrm{PCMB})\end{array}$ & $2007-2018$ & $\begin{array}{l}\text { «[...] la construcción } \\
\text { y rescate de espacios } \\
\text { públicos en barrios, } \\
\text { pueblos y colonias } \\
\text { populares de la capital». } \\
\text { (Gobierno de la Ciudad } \\
\text { de México, 2012). }\end{array}$ & $\begin{array}{l}\text { La falta de instituciona- } \\
\text { lización del PCMB un uso } \\
\text { para fines clientelares o en } \\
\text { función de los intereses polí- } \\
\text { ticos de los gobernantes en } \\
\text { turno (Ziccardi, 2012; Del- } \\
\text { gadillo, 2016). }\end{array}$ \\
\hline $\begin{array}{l}\text { Ley de Desa- } \\
\text { rrollo Urbano } \\
\text { de la Ciudad de } \\
\text { México }\end{array}$ & $\begin{array}{l}\text { 2010-aún } \\
\text { vigente }\end{array}$ & $\begin{array}{l}\text { Ordenar el desarrollo } \\
\text { urbano de la CDMX. } \\
\text { Establece figuras que } \\
\text { preveen la participación } \\
\text { del capital privado, } \\
\text { como los Sistemas de } \\
\text { Transferencia de Poten- } \\
\text { cialidades de Desarrollo } \\
\text { Urbano, las Áreas de } \\
\text { Gestión Estratégica } \\
\text { (AGE) ,los Polígonos de } \\
\text { Actuación y los Sis- } \\
\text { temas de Actuación por } \\
\text { Cooperación (SAC). }\end{array}$ & $\begin{array}{l}\text {-Participación de capital } \\
\text { privado en proyectos de } \\
\text { infraestructura urbana. } \\
\text {-Cambios de uso de suelo. } \\
\text {-Favorecen la inversion } \\
\text { inmobiliaria en proyectos de } \\
\text { infraestructura urbana. }\end{array}$ \\
\hline $\begin{array}{l}\text { Programas dele- } \\
\text { gacionales de } \\
\text { desarrollo urbano }\end{array}$ & $\begin{array}{l}\text { Diversos } \\
\text { periodos }\end{array}$ & $\begin{array}{l}\text { Establecer la planeación } \\
\text { del desarrollo urbano y } \\
\text { el ordenamiento terri- } \\
\text { torial de alcaldías (dele- } \\
\text { gaciones). }\end{array}$ & $\begin{array}{l}\text { Tienen los mismos efectos } \\
\text { que los programas generales, } \\
\text { pero con un énfasis parti- } \\
\text { cular en las condiciones de } \\
\text { cada alcaldía, }\end{array}$ \\
\hline
\end{tabular}

Fuente: Elaboración propia.

\section{Conclusión y discusión: ¿cuáles derechos? ¿para qué tipo de habitantes?}

En la ciudad neoliberal, tanto el derecho a la ciudad como el derecho a la vivienda se encuentran condicionados por las reglas del libre mercado, por los intereses económicos del sector financiero y por la disminución de 
la inversión estatal que cede terreno al capital privado. Desde la perspectiva de Lefebvre, tales condiciones limitan el pleno goce del derecho a la ciudad para los habitantes en situación precaria, ya que «para que los residentes vivan activamente la ciudad, y para que vivan bien - llevando una vida plena y digna - la ciudad, su hábitat debe de proveerles aquello que necesitan» (Purcell, 2009, p. 40; traducción libre).

Como se advierte en el caso de la Ciudad de México, el discurso político de los gobiernos de izquierda ha puesto énfasis en temas sociales, incluso desde 2007 se han comprometido a garantizar el derecho a la ciudad. Sin embargo, las acciones en el espacio urbano, tanto en la manera de producir y brindar acceso a la vivienda como en el tratamiento de los espacios a través de revitalizaciones, muestran una orientación contraria, ya que han favorecido principalmente los intereses de un sector privado, creando una ciudad cada vez más excluyente.

La realización de megaproyectos de infraestructura, la creación de barrios cerrados, la rehabilitación de sitios para fines turísticos, y todas aquellas acciones orientadas a insertar a la Ciudad de México en dinámicas globales, exacerban las desigualdades. De esta manera se limita el derecho de apropiación de los espacios urbanos mediante una privatización real o simbólica, y se permite el desarrollo inmobiliario residencial de carácter lucrativo, en detrimento de la vivienda de carácter social.

Aunque existen esfuerzos gubernamentales a nivel local que buscan brindar acceso a la vivienda a una población de bajos recursos, y que tratan de mejorar las condiciones de vida de los habitantes de zonas periféricas y marginalizadas de la ciudad, los resultados resultan limitados, sobre todo si se toma en consideración las disposiciones en materia de planeación y desarrollo urbano surgidas en un contexto de reestructuración económica. 


\section{Referencias}

Aguayo Ayala, A. (2016). El nuevo proyecto de ciudad: Del Centro Histórico a Santa Fe. Segregación, espacio público y conflicto urbano. En P. Ramírez Kuri (Ed.), La reinvención del espacio público en la ciudad fragmentada. Universidad Nacional Autónoma de México. 303-328

Aep (s/f). Acerca de. Recuperado de : https://aep.cdmx.gob.mx/dependencia/ acerca-de

BÉLANGer, H. (2008). Vivir en un centro histórico en Latinoamérica. Percepciones de los hogares de profesionales en la ciudad de Puebla. Estudios demográficos y urbanos, 23(2): 415-440.

BÉLANGER, H. (2018). Revitalisation des quartiers, appropriation des espaces publics et gentrifi cation : quel « droit à la ville» pour les résidents ? Dans Y. Emerich et L. Saint-Pierre Harvey (dir.), Accès à la terre et enjeux sociaux : précarité, territorialité, identité = Access to land and social issues : precarity, territoriality, identity (chap. 5, p. 119134). Montréal : Les Éditions Thémis.

Azuara, I., González, S., \& Tamayo Flores-Alatorre, S. (2007). Las Políticas habitacionales en el Distrito Federal: Una evaluación multidimensional. En S. Tamayo Flores-Alatorre (Ed.), Los desafios del Bando 2: Evaluación multidimensional de las políticas habitacionales en el Distrito Federal, 2000-2006 (pp. 21-27). Secretaría de Desarrollo Urbano y Vivienda, INVI-DF, UACM y Centro de Estudios Sociales y Culturales Antonio de Montesinos.

BIDou, C. (2003). Retours en ville: des processus de "gentrification» urbaine aux politiques de "revitalisation» des centres. Paris : Descartes.

Casgrain, A. \& Janoschka, M. (2013). Gentrificación y resistencia en las ciudades latinoamericanas el ejemplo de Santiago de Chile. Gentrification and resistance in latin american cities. The example of Santiago de Chile., 10(22), 19-44. DOI: 10.29092/uacm.v10i22.265

Chabrol, M,; Collet, A. \& Giroud M. (2016). Gentrifications. Paris: Amsterdam.

Coulomb, R. (2012). Evolución reciente y situación actual del derecho a la vivienda. En G. Garza \& M. Schteingart (Eds.), Los grandes problemas de México. Tomo 2. Desarrollo urbano y regional. El Colegio de México, 551-584.

Davidson, M., \& Lees, L. (2010, 2010/09/01). New-build gentrification: its histories, trajectories, and critical geographies. Population, Space and Place, 16(5), 395-411. https://doi.org/10.1002/psp.584 
Delgadillo, V. (2012). El derecho a la ciudad en la ciudad de México. ¿Una retórica progresista para una gestión urbana neoliberal? Andamios, 9, 117-139.

Delgadillo, V. (2014). La política del espacio público y del patrimonio urbano en la Ciudad de México: Discurso progresista, negocios inmobiliarios y buen comportamiento social. XIII Coloquio Internacional de Geocrítica El control del espacio y los espacios de control, Barcelona.

Delgadillo, V. (2016). El derecho a la ciudad en la Ciudad de México: Utopía, derechos sociales y política pública. En F. Carrión \& J. Erazo (Eds.), El derecho a la ciudad en América Latina. Visiones desde la política (pp. 73-90). Universidad Nacional Autónoma de México.

Delgadillo, V. (2017). Plan Integral de Manejo del Centro Histórico de la Ciudad de México. Un instrumento de gestión neoliberal. En Eftychia Bournazou (Ed.), Gentrificación. Miradas desde la academia y la ciudadanía (pp. 195-217). Universidad Nacional Autónoma de México. Facultad de Arquitectura.

Díaz Parra, I., \& Cuberos Gallardo, F. J. (2018). Políticas de higienización y gentrificación. Aportaciones desde el urbanismo latinoamericano. OBETS. Revista de Ciencias Sociales., 13(1), 289-316. https://doi.org/10.14198/OBETS2018.13.1.11

Duhau, E., \& Gigla, Á. (2010). El espacio público en la Ciudad de México. De las teorías a las prácticas. En G. Garza \& M. Schteingart (Eds.), Los grandes problemas de México.: Vol. II. Desarrollo urbano y regional. El Colegio de México, 390-447.

GLass, R. (1989). Clichés of urban doom and other essays. Oxford [England] ; New York, NY, USA: B. Blackwell.

Gobierno de la Ciudad de México. (2012). Programa Comunitario de Mejoramiento Barrial 2007-2012. Gobierno de la Ciudad de México. Secretaría de Desarrollo Social.

Hiernaux, D., \& González, C. I. (2014). Turismo y gentrificación: Pistas teóricas sobre una articulación. Revista de Geografia Norte Grande, $58,55-70$.

JANoschKa, M., \& Borsdorf, A. (2006). Condominios fechados and barrios privados: the rise of private residential neighbourhoods in Latin America. En G. Glasze, C. Webster \&K Frantz (Ed.), Private Cities. Global and Local Perspectives (pp. 92-108). London and New York: Routledge. 
Janoschka, M., Sequera, J., \& Salinas Arreortua, L. A. (2014). Gentrification in Spain and Latin America-A Critical Dialogue. International Journal of Urban and Regional Research, 38(4), 1234-1265. https://doi.org/doi: 10.1111/1468-2427.12030

Jones, G. A. \& Varley, A. (1999). «The Reconquest of the Historic Centre: Urban Conservation and Gentrification in Puebla, Mexico». Environment and Planning A 31 (9):1547-1566. doi: 10.1068/a311547.

LeEs, L.; Slater, T. \& Wyly, E. K. (2007). Gentrification. New York : Routledge/Taylor and Francis Group.

Lefebvre, H. (1968). Le droit à la ville . Paris: Anthropos.

LEY, D. (1996). The new middle class and the remaking of the central city. Toronto : Oxford University Press.

Lulle, T., \& Paquette, C. (2007). Los grandes centros comerciales y la planificación urbana. Un análisis comparativo de dos metrópolis latinoamericanas. Estudios Demográficos y Urbanos, 22(2), 337-361. http://dx.doi.org/10.24201/edu.v22i2.1282.

Olivera Martínez, P. (2014). Neoliberalismo en la Ciudad de México. Polarización y gentrificación. En R. Hidalgo \& M. Janoschka (Eds.), La Ciudad Neoliberal: Gentrificación y exclusión en Santiago de Chile, Buenos Aires, Ciudad de México y Madrid (pp. 151-177). Pontificia Universidad Católica de Chile.

Parnreiter, C. (2002). Ciudad de México: El camino hacia una ciudad global. EURE, 28, 89-119.

Parnreiter, C. (2011). Formación de la ciudad global, economía inmobiliaria y transnacionalización de espacios urbanos: El caso de Ciudad de México. EURE, 37(11), 5-24. https://dx.doi.org/10.4067/S0250$\underline{71612011000200001}$

Pattaroni, L., Kaufmann, V. \& Rabinovich, A. (2009). Habitat en devenir. Enjeux territoriaux, politiques et sociaux du logement en Suisse. Lausanne: PPUR.

Pérez Negrete, M. (2016). Ciudad de México: El camino recorrido en la conformación de una ciudad global. Revista Mexicana de Ciencias Politicas y Sociales, 61(226), 331-351. https://doi.org/10.1016/ $\underline{\mathrm{S} 0185-1918(16) 30013-7}$

Portal, A. M. (2016). El espacio público: ¿de quién y para quiénes? En P. Ramírez Kuri (Ed.), La reinvención del espacio público en la ciudad fragmentada (pp. 365-388). Universidad Nacional Autónoma de México. 
Puebla, C. (2007). Los programas de vivienda. En S. Tamayo Flores-Alatorre (Ed.), Los desafios del Bando 2: Evaluación multidimensional de las políticas habitacionales en el Distrito Federal, 2000-2006 (pp. 115-163). Secretaría de Desarrollo Urbano y Vivienda, INVI-DF, UACM y Centro de Estudios Sociales y Culturales Antonio de Montesinos.

Purcell, M. (2009). Le droit à la ville et les mouvements urbains contemporains. Rue Descartes. 63(1), 40-50. DoI:10.3917/rdes.063.0040.

Quiroz Rothe, H., \& Gómez, S. (2016). ¿Alternativo o excluyente? Percepción y tendencias en el uso del espacio público en un fragmento globalizado de la ciudad de México. En P. Ramírez Kuri (Ed.), La reinvención del espacio público en la ciudad fragmentada (pp. 233-268). Universidad Nacional Autónoma de México.

Redfern, P. A. (2003). What Makes Gentrification 'Gentrification'? Urban Studies, 40(12), 2351-2366. DOI: 10.1080/0042098032000136101.

Rose, D. (1994). Rethinking Gentrification: Beyond the Uneven Development of Marxist Urban Theory. Environment and Planning D: Society and Space, 2(1), 47-74. DoI: 10.1068/d020047.

Rose, D. (2010). Local state policy and 'new-build gentrification' in Montréal: the role of the 'population factor' in a fragmented governance context. Population, Space and Place, 16(5), 413-428. DoI: 10.1002/ psp.592.

Salinas Arreortua, L. A., \& Soto Delgado, L. (2019). Política de Vivienda en México: Entre la expansión y el retorno al centro. Investigaciones Geográficas. (99). https://doi.org/10.14350/rig.59751

Salinas Arreortua, L. A. (2013). Reciclamiento urbano: Como una premisa en la planeación del desarrollo urbano de la ciudad de México. GeoGraphos, 4(55), 564-580. DOI: 10.14198/GEOGRA2013.4.55.

Schteingart, M. (2016). Política de vivienda, organización del espacio y participación ciudadana . En F. Carrión \& J. Erazo (Eds.), El derecho a la ciudad en América Latina. Visiones desde la política (pp. 41-48). Universidad Nacional Autónoma de México.

Sмiтh, N. (1996). The new urban frontier: gentrification and the revanchist city. London; New York: Routledge.

Sмiтh, N. (2002). New Globalism, New Urbanism: Gentrification as Global Urban Strategy. Antipode, 34(3), 427-450. DoI: 10.1111/14678330.00249 . 
ZICCARDI, A. (2012). Espacio público y participación ciudadana: El caso del Programa Comunitario de Mejoramiento Barrial de la Ciudad de México. Gestión y política pública, 21(spe), 187-226. Recuperado en 20 de mayo de 2020, de http://www.scielo.org.mx/scielo.php?script=sci_arttext\&pid=S1405-10792012000300006\&lng=es\&tlng=es. 